\title{
Contenidos de cultura en las prácticas docentes y pedagógicas de lenguas extranjeras (PLE y ELE)
}

\section{Conteúdos de cultura nas práticas docentes e pedagógicas de línguas estrangeiras (PLE e ELE)}

\section{Cultural content in foreign language teaching and pedagogical practices (PFL and SFL)}

\author{
Ana Liza Bugnone* \\ Verónica Cecilia Capasso*
}

\begin{abstract}
RESUMEN
En la actualidad, se ha extendido una posición teórica y práctica que concibe la enseñanza de la lengua como parte de un proceso cultural, por lo que en las clases de portugués (PLE) y español (ELE) como lenguas extranjeras se incorporan aspectos de la cultura de la lengua-objetivo. Partimos de una concepción socio-antropológica de cultura y nos proponemos conocer el uso que se hace de contenidos ligados a la cultura de la lengua-objetivo en las clases de PLE y ELE, específicamente en asignaturas vinculadas a la lengua, gramática, fonética, fonología y lingüística aplicada. Para ello, realizamos un estudio descriptivo de las prácticas de las y los profesores de PLE y ELE de la Facultad de Humanidades y Ciencias de la Educación, en la Universidad Nacional de La Plata, a través de la realización de entrevistas semiestructuradas. Indagamos de qué modo las y los profesores utilizan contenidos respectivos a la cultura en sus clases, los aportes que consideran más relevantes, los recursos que utilizan y las modalidades pedagógicas que adoptan. Pretendemos avanzar en un estudio empírico sobre las efec-
\end{abstract}

" Universidad Nacional de La Plata. Facultad de Humanidades y Ciencias de la Educación. Buenos Aires, Argentina. E-mail: anabugnone@gmail.com. https://orcid.org/0000-0002-6674-717X. E-mail: capasso.veronica@gmail.com. http://orcid.org/0000-0003-3202-4106. 
tivas relaciones que entablan las y los profesores entre lengua y cultura y la productividad de este enfoque en sus prácticas docentes y pedagógicas.

Palabras clave: Enseñanza de lenguas extranjeras. Cultura. Español. Portugués. Prácticas docentes.

\title{
RESUMO
}

Atualmente tem se estendido uma posição teórica e prática que concebe o ensino da língua como parte de um processo cultural que leva as aulas de português (PLE) e espanhol (ELE) como língua estrangeiras a incorporarem aspectos da cultura da língua alvo. Partimos de uma concepção socioantropológica de cultura e nos propomos conhecer o uso que se faz de conteúdos ligados à cultura da língua alvo nas aulas de PLE e ELE - especificamente nas disciplinas ligadas à língua, gramática, fonética, fonologia e linguística aplicada. Para isso, realizamos um estudo descritivo das práticas das e dos professores de PLE e ELE da Faculdade de Humanidades y Ciencias de la Educación da Universidade Nacional de La Plata através da realização de entrevistas semiestruturadas. Indagamos de que maneira as e os professores utilizam os conteúdos ligados à cultura em suas aulas, as contribuições que consideram mais relevantes, os recursos que utilizam e as modalidades pedagógicas que adotam. Pretendemos avançar em um estudo empírico sobre as efetivas relações que engajam as e os professores de língua e cultura e a produtividade deste enfoque nas suas práticas docentes e pedagógicas.

Palavras-chave: Ensino de línguas estrangeiras. Cultura. Espanhol. Português. Práticas docentes.

\begin{abstract}
At present, there is a widespread theoretical and practical view that conceives language teaching as part of a cultural process, which is why certain aspects of the target-language culture are included in the teaching of Portuguese (PFL) and Spanish (SFL) as foreign languages. With a socio-anthropological conception of culture as our starting point, our aim is to understand how target-language culture-related content is used in PFL and SFL lessons, specifically in disciplines related to language, such as: grammar, phonetics, phonology and applied linguistics. In order to do so, we performed a descriptive study of PFL and SFL teaching practices at the School of Humanities and Education Sciences, Universidad Nacional de La Plata, by means of semi-structured interviews. We enquired about the way in which teachers use culture-related content in their lessons, the contributions that they consider most relevant, the resources they use and the pedagogical methods they adopt. Our goal is to make progress in an empirical study about the
\end{abstract}


effective relations built by teachers between language and culture and the productivity of this approach in their teaching and pedagogical practices.

Keywords: Foreign language teaching. Culture. Spanish. Portuguese. Teaching practice.

\section{Introducción}

En este artículo nos proponemos realizar un estudio descriptivo de las prácticas docentes de las y los profesores de portugués (PLE) y español (ELE) como lenguas extranjeras de la Facultad de Humanidades y Ciencias de la Educación de la Universidad Nacional de La Plata (FaHCE, UNLP). Partimos de una concepción socio-antropológica de cultura que implica tanto el modo de vida de una sociedad con sus normas y valores compartidos y heredados como los productos creativos que implican un contacto con la experiencia y generan nuevos significados. Así, nos proponemos conocer el uso que se hace de contenidos ligados a la cultura de la lengua-objetivo en las clases de PLE y ELE, específicamente en asignaturas vinculadas a la lengua, gramática, fonética, fonología y lingüística aplicada. Indagaremos de qué manera las y los profesores utilizan contenidos vinculados a la cultura en sus clases, los aportes que consideran más relevantes, los recursos que utilizan y las modalidades pedagógicas que adoptan. Así, pretendemos avanzar en un estudio empírico sobre las efectivas relaciones que entablan las y los profesores entre lengua y cultura y la productividad - y los límites - de este enfoque en sus prácticas docentes y pedagógicas.

La metodología de trabajo es cualitativa, a partir de la cual realizamos catorce entrevistas semiestructuradas, ya que se organizan en función de ciertas preguntas, permiten ser flexibles y no directivas, a la vez que son ventajosas principalmente en los estudios descriptivos y en las fases de exploración. Eso posibilita adaptarse a los sujetos, es decir, aclarar términos, identificar ambigüedades y reducir formalismos, así como permite que los informantes expresen sus puntos de vista de manera relativamente abierta. Las catorce entrevistas se realizaron con profesores de PLE que trabajan en el Profesorado en Portugués de la FaHCE y con docentes de ELE que en su mayoría dictan cursos de español para extranjeros, todos ellos activos al momento de la escritura de este artículo. Las entrevistas se realizaron durante los meses de julio y agosto de 2018.

La investigación se basa en el análisis de las siguientes variables: 1) la relevancia dada a los intereses de los estudiantes en la organización y en el desarrollo de las clases; 2) si se da la relación entre lengua y cultura y cuáles 
son sus modalidades; 3 ) los aportes que los contenidos de cultura generan en las distintas asignaturas; 4) los contenidos relacionados a la cultura que aparecen en las clases; 5) los tipos de recursos vinculados a la cultura; 6) el uso o no de estereotipos culturales; 7) los límites en el uso de este tipo de contenidos. Pondremos de manifiesto el importante papel del uso de contenidos culturales en las distintas asignaturas de PLE y ELE, señalando, a su vez, similitudes y diferencias de las distintas prácticas docentes. Ello nos permitirá avanzar en apreciaciones respeto no solo al rol fundamental de este tipo de contenidos y conocimientos para la competencia comunicativa de los aprendices de lenguas extranjeras, sino también para el fomento de una comprensión más profunda y crítica de la cultura de la lengua-objetivo y de la propia.

\section{La concepción socio-antropológica de cultura y la relación lengua/ cultura}

Desde los estudios culturales, Williams (2008) define la cultura como experiencia común u ordinaria del proceso social. Según esta concepción, se trata de la forma de vida de una sociedad con sus significados comunes, al mismo tiempo que las prácticas y producciones artísticas e intelectuales. Este autor sostiene que las sociedades tienen sus formas, finalidades, significados y orientaciones comunes, expresados en general en las artes, instituciones y saberes. Según Williams (2008), estos significados y orientaciones no son inmutables, ya que se encuentran bajo la presión de la experiencia y los descubrimientos que se inscriben en un territorio. El autor afirma que la cultura se forma en las sociedades y en las mentalidades. La construcción de las mentalidades se da a partir de dos procesos simultáneos: el lento aprendizaje de formas, propósitos y significados que hacen posible el trabajo y la comunicación, así como la experiencia, las nuevas observaciones, comparaciones y los significados. Entonces, según Williams (2008), la cultura tiene dos aspectos: una forma de vida, compuesta por los significados y las orientaciones conocidos, comunes $\mathrm{y}$ ordinarios (aspecto tradicional) y el quehacer creativo e innovador, es decir, nuevas observaciones y significaciones, individuales y más elaboradas. Allí se incluyen las artes y los conocimientos (aspecto creativo).

Desde la antropología, Foley (1997) señala que, en términos generales, la cultura se trata del comportamiento humano aprendido y enseñado, a diferencia de los animales, guiados por el instinto y la vida en la naturaleza. También afirma que está formada por prácticas con significado, es decir, que posee un potencial 
simbólico y lingüístico. Por otro lado, sostiene que ese comportamiento está arraigado en las relaciones sociales, en la medida en que no existe la cultura fuera de una sociedad. Así como no todas las sociedades son iguales, la base de la antropología es el reconocimiento de la diversidad de culturas. De esta manera, lo que mantiene unidos a los pueblos no es una información genética o biológica, sino la cultura. Foley (1997) sostiene que cuando hablamos de cultura, además de las tradiciones sociales heredadas, también la conforma nuestra visión del mundo.

Para completar el concepto de cultura, es interesante mencionar que, según Harris (2000), la cultura está formada por ideas y comportamientos de un sistema social. Según esta concepción materialista cultural, "la cultura es el modo socialmente aprendido de vida que se encuentra en las sociedades humanas y que abarca todos los aspectos de la vida social, incluidos el pensamiento y el comportamiento" (p. 17). Así, para este autor, ideas y comportamiento deben verse en una interrelación. Finalmente, es necesario señalar que la concepción socio-antropológica de cultura se posiciona, por un lado, contra el determinismo biológico y naturalista y, por otro, contra el idealismo, en la medida en que excede tanto la condición biológica de las personas como la pura autonomía del espíritu, oponiéndose al determinismo y al voluntarismo (Eagleton, 2001).

Esta perspectiva nos permite comprender la lengua como parte de la cultura tanto en su aspecto heredado y tradicional como creativo, al mismo tiempo en que implica normas compartidas socialmente y prácticas socioculturales. Como se sabe, la lengua no es desinteresada ni neutra, sino que el discurso está impregnado por el mundo social que lo envuelve (Moita Lopes, 1994). Así, "quem fala com alguém fala desde algum lugar específico e carrega todas as marcas de sua persona na construção do significado: papel sexual, classe social, raça etc. A linguagem não ocorre em um vácuo social” (Moita Lopes, 1994, p. 362). La lengua entendida como código neutro, fuera de las realidades en las que se desarrolla, ha dado paso a formas de concebirla donde se tienen en cuenta las situaciones concretas de la práctica social y los contextos socioculturales en que los individuos construyen sus visiones del mundo (Riva de Almeida, 2011). En la concepción de la lengua como discurso, se considera que hay múltiples interpretaciones posibles que se construyen tanto como las realidades y las visiones del mundo que las atraviesan. De este modo, en la enseñanza de lenguas extranjeras:

Precisamos não só compreender o código, mas, sobretudo, entender o contexto da interação e o uso de língua que se aplica àquele contexto. Em outras palavras, precisamos entender os aspectos culturais que constituem o contexto em que atuamos e que se materializam no uso da língua que fazemos, na qual estamos sempre construindo sentidos (Riva de Almeida, 2011, p. 32). 
Esta perspectiva implica que la relación entre lengua y cultura es indisociable, de modo que en la enseñanza de lenguas extranjeras es preciso reflexionar sobre la construcción de sentidos posibles dentro de una cultura determinada. Incluso es interesante señalar que los conflictos y las diferencias, lejos de ser anulados, forman parte del proceso educativo.

Por esta razón, el aprendizaje de una lengua no puede darse en abstracto, sin un contexto sociocultural. La pragmática define que la comunicación requiere una diversidad de datos e informaciones que permitan dar cuenta del uso específico del lenguaje en situación. El contexto es el lugar, el tiempo y la relación entre los participantes de una determinada interacción, así como el conjunto de supuestos (acerca del mundo, expectativas sobre el futuro, anécdotas, creencias etc.) que hablante y oyente utilizan en la interacción (Cortés y Menegotto, 1999). Sin embargo, Galindo Merino (2005) ha señalado que:

En el ámbito académico la enseñanza de la cultura ha tenido lugar tradicionalmente por separado con respecto a la lengua, y a menudo se ha restringido al estudio de la historia, el sistema político, las instituciones y el folklore, sin considerar aspectos culturales tan relevantes para la comunicación como las presuposiciones, los sobreentendidos, las opiniones y creencias y las pautas de conducta que determinan abiertamente la interacción comunicativa dentro de una determinada comunidad de habla (p. 435).

Esta afirmación nos resulta un punto de partida importante, ya que puede ser contrastada por esta investigación, en la medida en que es un paradigma que está cambiando en la enseñanza de lenguas extranjeras.

\section{Las prácticas docentes y pedagógicas de las y los profesores de PLE y ELE}

Cuando hablamos de la enseñanza, podemos establecer diferencias entre las nociones de práctica docente y práctica pedagógica (Barco, 2007). Con la primera, Barco se refiere al trabajo que el o la docente desarrolla cotidianamente en condiciones sociales, históricas e institucionales particulares que traspasan el aula y que tienden puentes con otras dimensiones (contexto, 
institución, historia del curso, inquietudes de las y los estudiantes, relación con otros docentes, diseños curriculares). Con práctica pedagógica, la autora alude al proceso desarrollado en el aula, en el que se pone de manifiesto la relación docente - conocimiento - alumno, centrada en el enseñar y aprender. Creemos que en ambas prácticas se pone en juego la relación lengua-cultura, como analizaremos más adelante.

En cuanto al vínculo entre la enseñanza y el o la docente, la acción de este último se caracteriza por estar orientada al logro de finalidades pedagógicas. Enseñar es una acción orientada hacia otros y realizada con los otros que implica un proceso de comunicación e intercambio no exento de tensiones. A su vez, el o la docente desempeña un papel de mediador entre las y los estudiantes y determinados saberes, facilitando el acceso a ciertos contenidos al promover la apropiación y el aprendizaje. En su rol, el o la docente se enfrenta a situaciones inéditas en escenarios donde puede haber tensiones, por lo que deben actuar inmediatamente.

La institución a la que hacemos referencia en este artículo, la FaHCE, ofrece, entre sus carreras de grado, el Profesorado en portugués, dependiente del Departamento de Lenguas y Literaturas Modernas. ${ }^{1}$ Por otro lado, el Área de Español como Lengua Segunda y Extranjera (ELSE) de la misma Facultad brinda la posibilidad para profesores graduados y/o en formación de realizar una Especialización en la enseñanza del español como lengua extranjera, por la que pasaron la mayoría de las docentes de ELE entrevistadas. Por último, se dan cursos de español para no hispanohablantes que tienen como objetivo la adquisición de las cuatro competencias: leer, hablar, escribir y escuchar. En suma, la FaHCE ofrece tanto formación de futuros docentes en lengua extranjera como cursos regulares de idiomas. Realizar esta diferencia es importante a la hora de identificar la presencia y el modo en que se utilizan los contenidos culturales. Los cursos regulares están orientados a la adquisición de herramientas para trabajar las competencias de la lengua, la comprensión y producción oral y escrita. Además, enfatizan en la formación cultural, abordando aspectos sociales, históricos y políticos de la lengua-objetivo. Los profesorados, si bien apuntan a esos mismos objetivos, suponen, además, una formación especializada con conocimientos de teorías, conceptos y núcleos de contenido fundamentales: formación lingüístico-literaria, formación didáctica y formación práctica (Madrid, 1998).

1 Se puede acceder al plan de estudios disponible en: http://www.fahce.unlp.edu.ar/academica/areas/lenguas-y-literaturas-modernas/carreras/profesorado-en-portugues. 


\section{Contenidos y usos de recursos ligados a la cultura}

En las entrevistas realizadas para esta investigación trabajamos con siete variables, cuyos principales resultados expresamos a continuación. Un primer punto relevante de la práctica pedagógica es el foco en el aprendizaje significativo, y con él la relevancia dada a los intereses del estudiantado. Según Galindo Merino (2005), es importante tener en cuenta la formación, gustos e intereses de las y los estudiantes, así como que los contenidos culturales se contextualicen y se relacionen con lo que ya saben. En suma, que sea un aprendizaje significativo para quienes estudian. Esto supone una reflexión previa por parte de la o el docente, vinculado con el interés, las necesidades de las y los alumnos y el nivel de lengua que tienen. Esta tarea de indagación y reflexión sobre los gustos e intereses de las y los alumnos está presente en la actividad docente de la mayoría de las y los entrevistados. Así, por ejemplo $\mathrm{C}^{2}$ propone:

Antes que nada, pregunto el interés del alumno y evalúo el nivel de Lengua (...). Como somos pocos - yo tengo cursos con 3, 4 y 5 alumnos - entonces puedo trabajar individualmente. Están los contenidos y los trabajo, pero muchas veces me salgo porque veo que el alumno necesita algo más, otra $\cos a(\mathrm{C}$, profesora de Lengua y Gramática Portuguesa).

En el mismo sentido, A y G, ambas profesoras de ELE, comentan que parten de las inquietudes que plantean las y los alumnos desde el primer acercamiento al aula. Incluso, es interesante señalar que las propias docentes se muestran curiosas de conocer la cultura de las y los estudiantes que provienen de diversos países y que consideran esta situación de intercambio como "intercultural". Allí también se manifiesta el interés de las y los alumnos por conocer las culturas de sus compañeros, por lo que la clase se va organizando en función de las inquietudes que surgen en el momento.

Según Rondón (2015), existen docentes que creen que la cultura puede enseñarse de forma independiente o paralela a la enseñanza de otros compo-

2 Hemos modificado los nombres de las y los entrevistados y colocado una letra al azar. Para ampliar la información de la cita de cada entrevista, hemos agregado la materia que dicta cada docente. En todos los casos se trata de comunicaciones personales realizadas entre julio y agosto de 2018. Para simplificar la lectura, hemos evitado colocar esta última información repetidamente en cada caso. 
nentes (gramaticales y lexicales). Sin embargo, la mayoría integra ambos tipos de contenidos, los cuales resultan más productivos y eficaces para que las y los estudiantes adquieran un conocimiento de esa lengua lo más aproximado posible al de los hablantes nativos (Rondón, 2015). Así, la segunda cuestión observada a partir de las entrevistas son las modalidades del uso de contenidos culturales en las clases de PLE y ELE. Es preciso decir que, en general, las y los entrevistados tienen en cuenta y proponen actividades orientadas a introducir cualquier aspecto sociocultural de la lengua-meta, ya sea en las clases de contenidos teóricos y en las clases prácticas. También ocurre que cuando la exposición de teorías no propicia el uso de contenidos culturales, ello se contempla en las horas de trabajos prácticos.

En relación con este punto, podemos identificar tres grupos diferentes. Un primer grupo está constituido por las y los docentes que no conciben la separación entre lengua y cultura, ya que consideran que la cultura atraviesa todo el contacto con el idioma, es decir que "lengua es lengua y cultura" $(\mathrm{H}$, profesor de Lingüística Aplicada), que "la cultura no es un contenido sino que es parte de la enseñanza" (A, profesora de ELE) y explican, por ejemplo, que "yo no sabría cómo separarlo, dónde está la lengua, dónde está la cultura" (I, profesora de ELE). Algunas citas de entrevistas clarifican este punto de vista:

De manera general, yo pienso que es imposible enseñar lengua sin enseñar cultura. O sea, sería reducir la gramática solo al análisis lingüístico y eso es imposible. No existe comunicación sino dentro de un contexto. Si, siempre trabajamos con cultura cuando trabajamos con lengua. Si leemos algún texto, inevitablemente estamos hablando de cultura también, porque hay mucho de una mirada ideológica de quien produce ese texto ( $\mathrm{J}$, profesora de Lengua y gramática portuguesa).

En el portugués sería imposible que no hubiese la cultura, y, de hecho, los alumnos nuestros, lo que más me parece que les gusta es salir de la clase típica y entrar en cosas culturales, porque en realidad él es un ser cultural y está esperando eso. (Entrevista a D, profesora de Fonética y fonología portuguesa).

(...) no es necesario recalcar que vamos a trabajar un texto que habla de cultura, sino que tengo todo mi cuerpo, toda manera de hablar. Porque yo pienso, sinceramente, que desde el momento en que entra un profesor extranjero para dar una clase, ya está: el contacto con otra cultura ya 
empezó. No es necesario que yo diga 'ahora vamos a hablar de cultura' (Entrevista a E, profesora de Lingüística aplicada en portugués).

En este grupo, como se ve en estos fragmentos de entrevistas, prima una concepción de cultura como la que desarrollamos al inicio de este artículo. Así, vemos especial relación con la posición que citamos de Williams (2008), en cuanto se concibe la cultura como algo "común" que aparece en todas las sociedades y mentalidades, así como constituye la forma de vida de un pueblo. Y se observa también, en este sentido, que la cultura es inseparable de la lengua como práctica social ya que, como señala Moita Lopes (1994), el discurso no se da en el vacío, sino en el marco del mundo social. Asimismo, en este grupo de entrevistas, es posible advertir una posición coincidente con la que sustenta Riva de Almeida (2011) cuando afirma que el lenguaje es un discurso y que, como tal, se construye socialmente, así como los contextos y las visiones del mundo.

En el segundo grupo, encontramos profesores y profesoras que si bien no consideran indisociable la relación entre lengua y cultura, utilizan frecuentemente contenidos ligados a esta última en sus clases, de manera que incorporan diversos elementos que hacen a la cultura de la lengua-objetivo a la par que van trabajando sobre temáticas específicas de su materia. Finalmente, hay quienes encuentran más dificultades para enseñar lengua y cultura de forma conjunta, en la medida en que relatan que los contenidos de las asignaturas que deben dictar no se vinculan directamente con aspectos de la vida real, o bien que refieren a cuestiones teóricas, gramaticales normativas o fonéticas, que según ellos, están escasamente relacionadas con la cultura.

Un tercer punto que emerge de las entrevistas es la postura de las y los docentes con respecto a los aportes que los contenidos de cultura generan a sus asignaturas. Aquí también encontramos tres grupos. En primer lugar, se ubican las visiones que parten de la idea de que los contenidos ligados a la cultura ayudan a orientarse en el comportamiento y entendimiento de la cultura otra. Esto se ve más frecuentemente en cursos regulares de lengua donde el aprendizaje apunta a un tipo de conocimiento que permita desarrollarse de manera más fácil en la cultura de la lengua-objetivo. Así, este tipo de contenidos, de modo más general, sirve:

Para que ellos tengan otras herramientas de cómo manejarse, entrar a un lugar y sepan cómo presentarse, cuando se acerca una persona cómo va a ser el trato, formal o informal, eso es fundamental. O sea, para un trabajo, para los amigos, cómo comportarse en un restaurante, en la facultad, en un banco (B, profesora de ELE). 
En estos casos podemos observar un tipo de aporte cultural en las clases de lengua que se asocia a la adecuación pragmática para resolver problemas en la comunicación (Míquel, 1999), desde una visión centrada en la competencia sociolingüística. En este sentido, la competencia cultural sería fundamental en el acto de comunicación, en el que aparecen elementos que exceden a la lengua y se relacionan con la adecuación pragmática.

En el segundo grupo, hay docentes que sostienen que los aportes de los contenidos culturales en sus materias contribuyen a que las y los futuros profesores de lengua piensen de una forma particular el binomio lengua/cultura. Es decir que promueven que las y los alumnos consideren ambos términos de manera articulada para su futura práctica docente, en el mismo sentido que el plantado en el apartado teórico, donde se hace hincapié en la condición de la lengua como indisociable de la cultura, en tanto se trata de una práctica social inmersa en determinados contextos culturales y en la que las y los interlocutores cargan sobre sí sus condiciones de clase, género, etnia etc. (Moita Lopez, 1994; Riva de Almeida, 2011; Cortés y Menegotto, 1999). Por ejemplo, según algunos docentes, este tipo de contenidos "ayudan a abrir nuevos caminos, hace que los alumnos tengan una nueva visión de lo que es la lengua, porque la lengua es cultura" (L, profesora de Didáctica Especial y Prácticas Docentes en Lengua Portuguesa). Asimismo, "no se trata de una clase que simplemente ve análisis lingüístico, o sea, hacemos análisis lingüístico de un texto auténtico que tiene relación siempre con la mirada ideológica o cultural de alguien" ( $\mathrm{J}$, profesora de Lengua y gramática portuguesa). Según otra docente:

En primer lugar, ellos están ante un input que es una muestra de lengua real, lengua en uso. No es algo producido artificialmente para un estudiante. En segundo lugar, porque en esa muestra de lengua confluye lo gramatical con lo cultural. Es raro que no se den de manera conjunta esas dos cosas (K, profesora de Técnicas de expresión en castellano).

Por último, identificamos un tercer grupo donde el tipo de aportes de los contenidos ligados a la cultura se vinculan con la posibilidad que brindan las y los alumnos a reflexionar sobre las características culturales e idiosincrásicas, tanto de su comunidad de pertenencia como de la lengua-objetivo. Así, algunas entrevistadas cuentan que los contenidos culturales "permiten abrir el juego para que reflexionen en torno a las idiosincrasias y de ahi podemos ir a lo más duro, es decir qué estructuras usamos y por qué" (F, profesora de ELE), así como "[en relación con la cultura], más allá de que hay cuestiones particulares, hay 
cuestiones que son más idiosincrásicas, más de la comunidad" (A, profesora de ELE). Esto significa que se considera fundamental el conjunto de ideas, comportamiento, actitudes, propios de un individuo, grupo o colectivo humano, que existen y se despliegan de modo naturalizado. Esto es lo que Cortés y Menegotto (1999) conciben central en el lenguaje, donde se ponen en juego las diversas concepciones sobre el mundo, creencias, las expectativas. Asimismo, como vimos, desde una perspectiva material de la cultura, Harris (2000) enfatiza en la interrelación entre normas, ideas y comportamiento.

Un cuarto punto que indagamos trata del tipo de contenidos culturales más utilizados en las clases. Partimos de que el componente cultural proporciona diferentes tipos de informaciones sobre la cultura de la lengua-objetivo. Por ejemplo, pueden tenerse en cuenta contenidos sociales, religiosos, artísticos, históricos y políticos. En este sentido, las y los profesores entrevistados mencionan la utilización de temas que asocian a la cultura, tales como: las comidas, las fiestas, los saludos, el uso de los medios de transporte, el tratamiento social en diferentes espacios y circunstancias, la vestimenta, la vida en las instituciones educativas, los géneros y las familias, los gustos y las preferencias, los gestos etc. En algunos casos se utilizan con fines prácticos que favorezcan la comunicación en el país de la lengua-objetivo, ya que cuestiones tales como la forma en que se organiza el transporte público o el nombre de los alimentos son necesidades primarias a la hora de vivir en un país que no es el propio. En otros casos, los contenidos son asociados a la idiosincrasia del país, lo que contribuye a la comprensión no solo de la lengua, sino de la forma de vida y de la visión del mundo de ciertos grupos. Asimismo, algunas profesoras entrevistadas consideraron que contenidos culturales no son elementos distinguibles, sino que atraviesan toda la clase, de modo que, por ejemplo, la propia presencia, el cuerpo, el modo de hablar ya implican estar en contacto con la cultura de la lengua-objetivo.

Los recursos elegidos para trabajar con estos contenidos son el quinto punto analizado a partir de las entrevistas. Estos son múltiples: audios de radio, videos, músicas, películas, documentales, textos literarios e históricos, fotografías, periódicos, historietas, imágenes. Además, entre los recursos actuales es indispensable internet. Así, por ejemplo, una entrevistada cuenta que:

[Uso] libros escolares, pasando por crónicas, por videos, películas. Siempre intento que los alumnos salgan un poco del mundo didáctico y vayan un poco a la realidad del país, y conozcan no solo Brasil en sí, sino todos los países de lengua portuguesa (...) Que estén preparados para la lengua extranjera pero que sean reales (L, profesora de Didáctica Especial y Prácticas Docentes en Lengua Portuguesa). 
En este caso, vemos que aparece también la relevancia de trabajar con materiales reales adaptados al aula, como noticias de diarios y periódicos, diálogos reales entre personas, entre otros. Esto, a su vez, permite aprovechar los contextos reales para presentar diferentes funciones comunicativas, lo cual colabora con el desarrollo de la competencia de las y los alumnos. Un ejemplo es el uso de sistema de mensajería Whatsapp, utilizado a través de los teléfonos inteligentes, que algunas docentes aprovechan para hacer escuchar mensajes reales o bien pedir a las y los alumnos que lo hagan. También se utilizan los hashtag (etiquetas creadas en las redes sociales) para analizar textos desde la lingüística aplicada. La utilización de internet en el aula es cada vez más usual entre las y los profesores entrevistados, de modo que el acceso a imágenes, videos e información se aplica para conocer tanto las inquietudes que salgan durante la clase, como aspectos más planificados. En el caso de las y los alumnos de niveles iniciales de lengua, el recurso de las imágenes de internet simplifica el aprendizaje, según algunas docentes entrevistadas, $\mathrm{y}$, además, permite la comunicación en los casos en que las y los estudiantes no conozcan la lengua-objetivo. Así, este recurso es útil, por ejemplo, cuando se trata de alumnos chinos o japoneses y la distancia entre la lengua materna y la lengua-objetivo es enorme.

El sexto punto sobre el cual trabajamos en las entrevistas se relaciona con los estereotipos. Según Galindo Merino (2005), un tipo de ejercicio destinado a trabajar el componente sociocultural en clase incluye actividades dirigidas a evidenciar con las y los alumnos los prejuicios culturales y la existencia de estereotipos, con el fin de romperlos. Esto genera conciencia sobre la existencia de estereotipos acerca de las distintas nacionalidades, a la vez que fomenta un análisis comparativo de culturas, visibilizando las diferencias culturales. En las entrevistas realizadas, cuando se preguntó sobre la utilización de estereotipos, en su mayoría se posicionó en la necesidad de deconstruirlos y sostiene que hay que derribarlos, ya que no aportan a la enseñanza en general.

Según Gutiérrez e Ibáñez (2013), "los estereotipos son imágenes simplificadas sobre personas o grupos que son compartidas por un gran número de personas" (p. 110), son descripciones que se realizan sin tener un profundo conocimiento acerca de estos grupos y que se basan en características como la procedencia social, ideología, opción religiosa, género, edad, grupo étnico, formativo, entre otras. Los estereotipos conllevan un encasillamiento de las personas o grupos y la atribución de cualidades muchas veces negativas. Además, "el estereotipo es el paso previo al prejuicio, que a su vez antecede a la discriminación” (Malgesini y Giménez en: Ibáñez y Gutiérrez, 2013, p. 111). Entonces, cuando aparecen estereotipos en las clases de lengua extranjera, un profesor explica que "la idea es deconstruirlos. Siempre relativizando todo, 
tratando de no crearlos" (H, profesor de Lingüística Aplicada). En el mismo sentido, otra docente afirma que:

[Es preciso romper] esa visión de que hay una lengua estereotipada, que hay una lengua correcta y que es la del colonizador (...) Trato de romper con eso, y siempre trabajo con esos estereotipos pero para pensarlos (...) para explicar todo el contexto que hay alrededor de eso. (J, profesora de Lengua y gramática portuguesa)

Además, en particular, hay docentes que se concentran en hacer una crítica a los estereotipos nacionales, mostrar la diversidad de culturas que conviven en un país y evitar la totalización y la homogeneización que cristaliza una única mirada sobre sus habitantes, sus costumbres, hábitos, gustos, etnias, formas de vida, entre otros. Así, algunas docentes proponen:

Ver también ciertos estereotipos culturales desde su propia cultura, para que ellos reconozcan, por ejemplo, cómo se ve un francés, un italiano, un japonés, un chino en Argentina y cómo ellos ven a los argentinos y tratar de ver especialmente las diferencias que hay o las subculturas dentro de lo que sería la cultura argentina. (K, profesora de Técnicas de expresión en castellano)

[Dar cuenta de que] Brasil es inmenso, hay un diferencia muy grande entre las provincias (...) Fue colonizado por un montón de otras culturas. En el sur, mi familia es polaca, hay ucranianos, alemanes. Entonces eso influye un montón y eso hace que seamos muy distintos del norte de Brasil en donde sí se quedaron un montón de portugueses y después fueron llegando africanos, entonces es obvio que tenemos otra manera de compartir (E, profesora de Lingüística Aplicada en portugués).

Estas visiones pueden enmarcarse en un proceso de cambios que Hall (2010) define como una "crisis de identidad", la cual "es parte de un proceso más amplio de cambio que está dislocando los procesos y estructuras centrales de las sociedades modernas y minando las bases que otorgaban a los individuos un anclaje estable en el mundo social" (p. 367). Así, se trata de una posición que complejiza las identidades culturales y, más que estabi- 
lizarlas o definirlas de una vez y para siempre, se centran en las diferencias e hibridaciones que las conforman.

Finalmente, en un caso, se sostiene que los estereotipos no son del todo negativos en la enseñanza de la lengua, ya que permiten trabajar sobre las expectativas de las y los alumnos. Es decir, se identifica que las y los estudiantes de lengua extranjera, particularmente en el caso de los cursos regulares, comienzan a estudiarla a partir de las ideas e imágenes pre-construidas que tienen sobre esa cultura otra. Así, los estereotipos funcionarían como punto de partida para adentrarse al estudio de otra lengua/cultura para reconocer "cierto jeito, como lo llamamos, una forma de ser", y, en el devenir de las clases, "hay determinados estereotipos que uno tiene que ir de a poco deconstruyendo, hay que hacer un camino" (D, profesora de Fonética y fonología portuguesa).

Por último, el séptimo punto que aparece en las entrevistas es si existe o no un límite en el uso de contenidos culturales, el cual puede estar dado tanto por cuestiones temáticas como por los tiempos acotados de las clases. En este punto ubicamos tres grupos de docentes. El primero considera que no hay un límite, pues ese tipo de contenidos "permea toda la clase" (L, profesora de Didáctica Especial y Prácticas Docentes en Lengua Portuguesa), por lo que cualquier tema que surja en la clase o que proponga el o la docente de índole sociocultural, es considerado pertinente. Un segundo grupo plantea que los límites están dados por el abordaje de temas polémicos o que puedan incomodar a las y los estudiantes, como el aborto y la muerte de seres queridos, que generan expresiones que algunos alumnos y alumnas no consideran oportunas en sus propias culturas. Por ejemplo:

Hay ciertos temas espinosos que no se tocan, ahora el tema en la Argentina es la legalización del aborto, y ese es un tema que yo no llevo a la clase salvo que lo saquen ellos, porque hay cuestiones que son muy personales y uno tiene que ser muy cuidadoso (A, profesora de ELE).

Esto se relaciona con que en las clases de español, a partir de la diversidad de culturas de las que provienen las y los estudiantes, según la docente, "la cuestión convivencial también es fundamental, al menos en el curso de Español I, es muy importante que ellos se sientan cómodos, que se conozcan, que puedan encontrar puntos en común" (A, profesora de ELE).

El tercer grupo de docentes entiende que hay un límite dado por los contenidos de los programas de sus materias, ya que exceden a la enseñanza de la lengua e incluyen teorías y conceptos para las y los futuros profesores de lengua. 
En estos casos, se evita que la clase se vaya del tema y no se focalice en los contenidos mínimos obligatorios. Así, se encuentran dificultades a la hora de integrar lengua y cultura: "el límite de extensión tiene que ver con el tiempo y la atención (...) y de mi conocimiento. (...) [Y se relacionan también] un poco con la pertinencia" (M, profesora de Lengua y gramática portuguesa). Aquí hay una diferencia entre quienes tienen que dar temas teóricos en sus materias (en particular quienes enseñan español y portugués a futuros docentes) y quienes dictan cursos de español a no hispanohablantes, donde, en general, no hay ese tipo de contenidos. Esta limitación es notable, ya que en general no es expresada en la bibliografía de referencia sobre la relación entre lengua y cultura en la enseñanza de lenguas extranjeras, por lo que es interesante tener en cuenta que no siempre es posible un abordaje conjunto, en cuanto hay docentes que deben dictar teorías y aspectos técnicos que no encuentran un lugar en un abordaje sociocultural.

En síntesis, el análisis de las prácticas docentes que hemos realizado hasta aquí nos ofrece un panorama diverso de las modalidades de enseñanza y aprendizaje de lenguas extranjeras. Avanzaremos, entonces, con las conclusiones, donde repondremos las ideas centrales sobre la relación entre lengua y cultura en los casos de PLE y ELE en la FaHCE, UNLP.

\section{Conclusiones}

En este artículo partimos de una concepción socio-antropológica de cultura, perspectiva que nos permite comprender la lengua como parte de un proceso cultural. Es decir, nuestro punto de inicio es que existe una relación indisociable entre lengua y cultura. Ahora bien, con base en un estudio empírico se abordaron las relaciones entre lengua y cultura que las y los profesores de PLE y ELE conciben y efectúan, así como la productividad y límites de este enfoque. Vimos que, en general, las y los profesores entrevistados tienen en cuenta y proponen actividades orientadas a introducir cualquier aspecto sociocultural de la lengua extranjera, aunque con diferentes modalidades. De esta manera, hay quienes no conciben la separación entre lengua y cultura y esta postura se despliega durante toda la clase, hay otros que proponen un uso frecuente de temas relacionados con la cultura, y, por último, están aquellos que en sus clases utilizan de manera escasa este tipo de contenidos (ya sea por una cuestión disciplinar o porque no ven vínculos entre los temas impartidos y la vida real). Por otra parte, identificamos que las y los docentes tienen diferentes posturas respecto a la contribución que los contenidos de cultura generan a sus asignaturas. Estos aportes sirven 
para orientar a las y los estudiantes en el comportamiento y entendimiento de la cultura otra, o para comprender el binomio lengua/cultura, o para reflexionar sobre las características de la comunidad de pertenencia y de la lengua-objetivo. Observamos también que los contenidos culturales abordados por las y los profesores, por un lado, incluyen desde temas ligados a lo social, religioso, artístico, histórico y político hasta cuestiones vinculadas a la vida cotidiana y, por otro lado, promueven el uso de diferentes tipos de recursos (visuales, audiovisuales, literarios, virtuales etc.). Señalamos, además, el objetivo de deconstruir estereotipos y, por último, los límites existentes en el uso de contenidos culturales. Es importante señalar que el análisis de las entrevistas realizadas nos permitió ver que no siempre son utilizados contenidos y recursos ligados a la cultura, pues existen límites temporales y temáticos que muchas veces funcionan en las clases como demarcación de lo que se aborda o no en ellas.

Para terminar, en algunos casos, vemos una diferencia entre la forma en que se vincula lengua y cultura en las clases regulares de lengua extranjera y la que ocurre en las que se forma a futuros profesores, ya que en este último caso, además del estudio de la lengua, incluyen otro tipo de reflexión sobre la misma, así como contenidos gramaticales, lingüísticos, fonéticos y teóricos que implican - según la percepción de estos docentes - una limitación al abordaje del binomio lengua-cultura. En cambio, surgió de las entrevistas que otras y otros docentes que enseñan español o portugués como lengua extranjera en cursos regulares de idiomas, se mueven con mayor libertad en la organización de las clases y en la apropiación de temas culturales que surgen en el contexto del aula. Asimismo, en estos casos, así como en otros que también imparten clases a futuros docentes, observamos que la relación lengua-cultura se manifiesta de forma inseparable. En suma, el contexto de enseñanza y aprendizaje de lenguas extranjeras aparece como un espacio propicio para el desarrollo de una competencia inter y sociocultural, aunque, en asignaturas o clases puntuales se dificulte generar el vínculo entre lengua y cultura.

\section{REFERENCIAS}

Barco, S. (2007) Otra vuelta de tuerca: revisitando documentos curriculares y prácticas en la formación docente ¿Es que hay algo distinto? En: J. C. Balbi (Coord.). Informe sobre el desarrollo humano en la provincia de Buenos Aires, 2006-2007. (pp. 67-84). Buenos Aires, Argentina: EUDEBA. 
Cortés, A. y Menegotto, A. (1999) La importancia de la competencia sociocultural en el aprendizaje de las lenguas. X Congreso Internacional de la ASELE Nuevas Perspectivas en la Enseñanza del Español como Lengua Extranjera, Cádiz, España.

Eagleton, T. (2001). La idea de cultura: una mirada política sobre los conflictos culturales. Barcelona, España: Paidós.

Foley, R. (1997). Antropologia. En: W. Outhwaite y T. Bottomore (Ed.). Versão brasileira: R. Lessa e W. G. Dos Santos (Ed.). Dicionário do pensamento social de século XX. (pp. 22-27). Rio de Janeiro, Brasil: Jorge Zahar Ed.

Galindo Merino, M. M. (2005). La importancia de la competencia sociocultural en el aprendizaje de segundas lenguas. Interlingüistica, (16), 431-441.

Gutiérrez Esteban, P. y Ibáñez Ibáñez, P. (2013). ¿Cómo se transmiten los estereotipos culturales y sexistas a través de las imágenes de las tic en los libros de texto? Enseñanza \& Teaching, 31, 109-125.

Hall, S. (2010). Sin garantías: Trayectorias y problemáticas en estudios culturales. Popayán, Colombia; Lima, Perú; Bogotá, Colombia; Quito, Ecuador: Universidad Javeriana, Instituto de Estudios Peruanos, Universidad Andina Simón Bolívar, Envión Editores.

Harris, M. (2000). Teorías sobre la cultura en la era posmoderna. Barcelona, España: Crítica.

Madrid, D. (1998). Función docente del profesorado de idiomas. En: C. Gómez Castro y M. Fernández Cruz (Coords.). La Función docente en Educación Infantil y Primaria desde las Nuevas Especialidades. (pp. 216-226). Granada, España: Grupo Editorial Universitario.

Miquel, L. (1999). El choque intercultural: reflexiones y recursos para el trabajo en el aula. Carabela, 45, 27-46.

Moita Lopes, L. P. da (1994). Linguagem, interação e formação do professor. Revista Brasileira de Estudos Pedagógicos, 75(179/180, 181), 301-371.

Riva de Almeida, M. (2011) Um olhar intercultural na formação de professores de línguas estrangeiras. Tese Doutorado em Letras. Universidade Federal do Paraná, Curitiba, Brasil.

Rondón, W. (2015) La cultura como herramienta para la enseñanza del español como lengua extranjera. 4to Encuentro Internacional de español como lengua extranjera, Enseñanza, aprendizaje y evaluación. Bogotá, Colombia.

Williams, R. (2008) Historia y cultura común. Antología. Raymond Williams. Madrid, España: Los Libros de la Catarata.

Texto recibido el 21 de septiembre de 2018.

Texto aprobado el 08 de marzo de 2019. 